\title{
Load Response Towards Voltage In TNB Power System Using The Measurement Approach
}

\author{
Abdul Halim Abu Bakar, MIEEE, Sallehhudin Yusof, Senior Member IEEE, Malini Satchiananda, Saad Mekhilef
}

\begin{abstract}
This paper reports the load-voltage dependency using field measurements for a faulted condition that caused a momentary voltage sag in a Tenaga Nasional Berhad network in the Central Region. The static load model is used in this study and its suitability is discussed in comparison to the dynamic load model. A fast method of calculating real and reactive power based on available information is devised. Propagation of fault through transformers is also investigated. The effect of voltage on real and reactive power is discussed at great length. Various factors influence the load characteristic, including weather, time of day, network conditions and type of feeder load. Long-term steady state data should be made available for analysis to back up results from this study.
\end{abstract}

\section{INTRODUCTION}

The global electric power demand is rapidly increasing. The increasing disparity between demand of energy and supply leads to a number of concerns in relation to the present and future availability of energy sources in the world, the environmental costs that will be associated to this growth, and how third world countries will handle the increasing energy needs of their growing populations [1]. The power industry depends more and more on the industry growth rate and the use of the existing capacity in the most effective way. Therefore current challenges in power engineering include optimizing the use of the available resources and keeping high reliability for operating conditions that will include narrow stability and security margins [1].

Changes in the power generation and transmission systems, optimizing the available resources while making environmental consideration, and ensuring high reliability in the system operation, are necessary in order to match the increasing demand in the load areas. The system planning must ensure controllable generation for regulating both frequency (by controlling the output of the active power) and voltage (by controlling the output of reactive power), and must control the costs and ability to operate as spinning reserves when needed. An optimization and coordination of the available resources, as well as the construction of new generation plants will thus be necessary.

The fact that loads are generally voltage dependent is a critical aspect for the planning and operation of the power system. The load characteristic may result in a very optimistic or pessimistic design if it is not chosen appropriately, leading the system to voltage collapse or on the other hand to very over-sized security margins.

\section{LOAD MODELING}

The interest in load modeling has been continuously increasing in the last years, and power system load has become a new research area in power systems stability. We now realize that load-voltage characteristics have a significant effect on system performance, and transient stability results are known to be highly dependent upon the load characteristics assumed [2]. Several studies have shown the critical effect of load
Two main approaches to load model development have been considered by the electric utility industry [3]. They are as follows:-

\section{A. Measurement-Based Approach}

The measurement-based approach involves placing monitors at various load substations to determine the sensitivity of load active and reactive power to voltage variations to be used directly, or to identify parameters for more detailed load models [2] [4]. This approach has the advantage of direct monitoring of the true load and can produce load model parameters directly in the form needed for power flow and transient stability program input. Its disadvantages include the cost of acquiring and installing the measurement equipment and the need to monitor all system loads or to extrapolate from limited measurements.

\section{B. Component-Based Approach}

The component-based approach involves building up the load model from information on its constituent parts. Three sets of data are required; load class data, load composition data and load characteristic data. Load class data describes a category of load such as residential, commercial or industrial. For load modeling purposes, loads are classed accordingly. Each class has a similar load composition and characteristics. Load composition data describes the fractional composition of the load by load components. This term can be applied to bus load or a specific load class. Load characteristic data is a set of parameters such as power factor, variation of active and reactive power with voltage, etc. It characterizes the behavior of a specific load. The component-based approach has the advantage of not requiring system measurements and therefore being more readily put into use. Since load characteristics and load composition data should not vary widely over a particular system, they can be developed once for the entire system. Only the load class mix data needs to be prepared for each bus or area and updated for changes in the system load [2].

A combination of both the measurement-based approach and the component-based approach is best to come to a conclusion on the inherent load characteristic.

The static load model has been used widely for the past many years, even to approximate dynamic components. It is not dependent on time and therefore it describes the relationship of the active and reactive power at any time with the voltage and/or frequency at the same instant of time

The dynamic model has lately been employed by a number of utilities, especially regions with 4 seasons that use high amounts of heating loads at certain junctures of the year [1][4][5]. It expresses this relationship at any instant of time, as a function of the voltage and/or frequency time history, including normally the present moment.

The 3 main load models explored in this research are as follows. These are the main load models that have been developed and used in the recent past by various researchers throughout the world. 


\section{A. Polynomial Static Load Model}

This is a branch of the static model that represents the power relationship to voltage magnitude as a polynomial equation, usually in the following form [3]:-

$$
\begin{aligned}
& \mathrm{P}=\mathrm{P}_{0}\left[\mathrm{a}_{1}\left(\mathrm{~V} / \mathrm{V}_{0}\right)^{2}+\mathrm{a}_{2}\left(\mathrm{~V} / \mathrm{V}_{0}\right)+\mathrm{a}_{3}\right] \\
& \mathrm{Q}=\mathrm{Q}_{0}\left[\mathrm{a}_{4}\left(\mathrm{~V} / \mathrm{V}_{0}\right)^{2}+\mathrm{a}_{5}\left(\mathrm{~V} / \mathrm{V}_{0}\right)+\mathrm{a}_{6}\right]
\end{aligned}
$$

The parameters of this model are the coefficients $\left(a_{1}\right.$ to $\left.a_{6}\right)$. This model is referred to as the ZIP model, since it consists of the sum of constant impedance $(\mathrm{Z})$, constant current (I), and constant power (P) terms. The model has been implemented in [6].

\section{B. Exponential Static Load Model}

This is another branch of the static load model that represents the power relationship to voltage as an exponential non-linear equation, usually in the following form [3]:-

$$
\begin{aligned}
& \mathrm{P}=\mathrm{P}_{0}\left(\mathrm{~V} / \mathrm{V}_{0}\right)^{\mathrm{np}} \\
& \mathrm{Q}=\mathrm{Q}_{0}\left(\mathrm{~V} / \mathrm{V}_{0}\right)^{\mathrm{nq}}
\end{aligned}
$$

The parameters of this model are the exponents, np and nq. By setting these exponents to 0,1 or 2 , the load can be represented by using constant power, constant current, or constant impedance models respectively. Other exponents can be used to represent the aggregate effect of different types of load components as expressed in [3][7].

\section{Exponential Dynamic Load Model}

Due to the large amount of electrical heating loads in 4-season countries, and its critical effect on voltage stability a load model with exponential recovery has been proposed [5]. The model is presented below, as a set of non-linear equations, where real and reactive power has a non-linear dependency on voltage.

$$
\begin{gathered}
P_{l}=P_{r}+P_{o}\left(\frac{V}{V_{o}}\right)^{a_{t}} \\
T_{p} \frac{d P_{r}}{d t}+P_{r}=P_{o}\left(\frac{V}{V_{o}}\right)^{\alpha_{s}}-P_{o}\left(\frac{V}{V_{o}}\right)^{\alpha_{t}}
\end{gathered}
$$

Here, $V_{0}$ and $P_{0}$ are the voltage and power consumption before a voltage change. $P_{r}$ is the active power recovery, $P_{1}$ is the total active power response, $T_{p}$ is the active load recovery time constant, $\alpha_{t}$ is the transient active load-voltage dependence, and $\alpha_{s}$ is the steady state active load-voltage dependence. Similar equations are also valid for reactive power.

For this research, the exponential static load model is used. This would be a natural progression since the constant power load model is currently implemented in TNB power systems. Based on previous works, the results obtained using the static model and dynamic model does not pose much differences if the amount of heating loads are minimal and the voltage deviation of the system is not too drastic [1].

\section{DATA}

The data obtained for this study is the voltage and current readings due to a fault that occurred on Saturday, $21^{\text {st }}$ January 2006 at approximately $10.28 \mathrm{am}$. The double phase to ground fault occurred at a $275 \mathrm{kV}$ overhead line (L2), which connects KL South (KULS) and Serdang (SRDG), both of which are major substations in the Central KL region. Weather during the incident was fine.
ION 7600 Power Quality Monitoring System (PQMS) installed at various $33 \mathrm{kv}$ feeders in the Central Region recorded the RMS and sinusoidal voltage and current deviations during the fault event. This is the first time PQMS data is being used to evaluate loadvoltage characteristics. Previously, data was only used to analyze voltage sag index for important customers in the region.

The fault incident affected 13 feeders. They are BJLL4L5, BTGA2L5, HCOM3L5, KLJT8L5, MERU4L5, NUNI13L5, PIDH2L5, PIST6L5, PMJU7L5, PROT3L5, SHAE8L5, SRDG1L5 and TMSY2L5.

\section{A. Determination of Phase Angle}

Since data is sampled at standard 32 samples per cycle, a mathematical calculation of phase angle between voltage and current is devised based on the zero-crossing technique. Microsoft Excel is used.

The 2 successive points where the data changes from positive to negative for both phase voltage and current is of interest in the tabulation. The change indicates that the zero crossing occurs in between these 2 values. The actual value needs to be calculated. It is found that points close to zero crossing of the waveform form a linear line. Figure 1 illustrates the linear line observed when 6 data points of red phase sinusoidal voltage (VRpp) is plotted during zero crossing.

Figure 1 : Linear Line during Zero Crossing

With this, the value of the point that cuts through zero can be accurately calculated via mathematical formulation using the

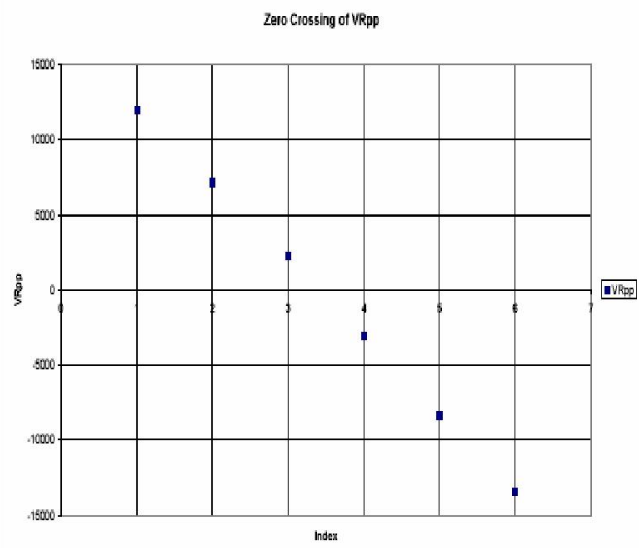

fundamentals of linear line equations. The slope of the line is a constant value, thus we can use the following equation:-

where,

$$
(\mathrm{V}-0) /\left(\mathrm{V}-\mathrm{V}_{1}\right)=\mathrm{V}_{\mathrm{z}}
$$

$\mathrm{V}=$ last positive point of $\mathrm{VRpp}$

$\mathrm{V}_{1}=$ first negative point of VRpp

$\mathrm{V}_{\mathrm{z}}=$ VRpp data point at zero crossing

The similar principal is used for phase current. The equation is as follows:-

where,

$$
(\mathrm{I}-0) /\left(\mathrm{I}-\mathrm{I}_{1}\right)=\mathrm{I}_{\mathrm{z}}
$$

$\mathrm{I}=$ last positive point of IRpp

$I_{1}=$ first negative point of IRpp

$\mathrm{I}_{\mathrm{z}}=\mathrm{IRpp}$ data point at zero crossing 


\begin{tabular}{|c|c|c|c|}
\hline VRpp & IRpp & phi & \\
\hline 11923.01 & 200.9045 & & \\
\hline 7173.327 & 154.372 & & \\
\hline 2228.448 & 99.9792 & 1.424148607 & $Y_{\text {nwp }}$ \\
\hline 3025.485 & 9522583 & 2.515151515 & $I_{\operatorname{mpp}}$ \\
\hline-831125 & -33.15372 & 1.091002900 & $\Delta$ \\
\hline-13403.22 & 97.90709 & $12.2737 \mathrm{~B} 272$ & $\theta$ \\
\hline$-17 \% 25.18$ & -1600.0703 & 0.21421792 & rod \\
\hline-21795.5 & -211.355 & 0.97714295 & cosfind \\
\hline 24512.95 & 253.6332 & 0.21256329 & sinfrad) \\
\hline-2618833 & -284023 & & \\
\hline
\end{tabular}

Figure 2 : Example of Excel Computation of Phase Angle

The difference between space units of VRpp and IRpp can be computed. A step approach is implemented for ease of Excel calculation. Referring to Figure 2, since voltage is leading current in this case, VRpp is treated as the first unit. It can be seen that IRpp is 2 steps behind VRpp. Thus the formula is as follows:-

$$
\begin{aligned}
& V_{\text {zstep }}=V_{z}+1 \\
& I_{z \text { step }}=I_{z}+\left(\text { no. of cells away from } V_{z}\right)
\end{aligned}
$$

However, in the event that current leads voltage, IRpp is treated as the first unit and the following equation applies:-

$$
\begin{aligned}
& I_{\text {zstep }}=I_{z}+1 \\
& V_{\text {zstep }}=V_{z}+\text { (no. of cells away from } I_{z} \text { ) }
\end{aligned}
$$

The difference between the cells is established. In this case current is always used as the reference point no matter whether it leads or lags voltage. The equation is as follows:-

$$
\Delta=I_{\text {zstep }}-V_{\text {zstep }}
$$

Now, $\Delta$ has to be changed from units to degrees. Since the sampling rate is 32 samples per cycle, the following equation is used:-

$$
\theta=(\Delta / 32)^{*} 360^{\circ}
$$

Since Excel only recognizes radians and not degrees in its mathematical formulation, the next step is to convert as follows:-

$$
\mathrm{rad}=\theta^{*}\left(\Pi / 180^{\circ}\right)
$$

Finally, the sine and cosine of the phase angle in radians is ready to be computed. By copying all these formulas in respective columns, the varying phase angle can be tabulated easily. The formulation of Real and Reactive Power proves to be an easy task as all the relevant information is available. The following equations are used:-

$$
\begin{aligned}
& \text { Real Power, } P=V_{\mathrm{rms}} * I_{\mathrm{rms}} * \cos (\mathrm{rad}) \\
& \text { Reactive Power, } \mathrm{Q}=\mathrm{V}_{\mathrm{rms}} * \mathrm{I}_{\mathrm{rms}} * \sin (\mathrm{rad})
\end{aligned}
$$

\section{NON-LINEAR LEAST SQUARE REGRESSION}

Non-linear regression is used when a best fit needs to be computed to a set of data with an inherent non-linear equation attached to it. The main difference between linear and non-linear regression is that the solution must proceed in an iterative fashion. Looking at the static load model, it can be linearized by taking its base-10 logarithm to give the following equation:-

$$
\begin{aligned}
& \log \left(\mathrm{P} / \mathrm{P}_{\mathrm{o}}\right)=n p \log \left(\mathrm{V} / \mathrm{V}_{\mathrm{o}}\right)+\mathrm{c} \\
& \log \left(\mathrm{Q} / \mathrm{Q}_{\mathrm{o}}\right)=n q \log \left(\mathrm{V} / \mathrm{V}_{\mathrm{o}}\right)+\mathrm{c}
\end{aligned}
$$

In their transformed forms, these models can use linear regression to evaluate the constant coefficients. They could then be transformed back to their original state and used for predictive purposes. This has been done in previous works [3][5]. The problem is that the transformation distorts the experimental error. Linear regression assumes that the scatter of points around the line follows a Gaussian distribution and that the standard deviation is the same at every value of $V$. These assumptions are rarely true after transforming data. Furthermore, some transformations alter the relationship between $\mathrm{V}$ and $\mathrm{P}$. Thus, non-linear regression is employed.

To remove the subjectivity of the chosen method, some criterion must be devised to establish a basis for the fit.

\section{A. Residual Analysis}

The residuals from a fitted model are defined as the differences between the response data and the fit to the response data at each predictor value.

$$
\mathrm{r}_{i}=\mathrm{y}_{i}-\mathrm{y}_{i}
$$

Assuming the model fitted to the data is correct, the residuals approximate the random errors. Therefore, if the residuals appear to behave randomly, it suggests that the model fits the data well. However, if the residuals display a systematic pattern, it is a clear sign that the model fits the data poorly.

\section{B. Sum of Squares Due to Error (SSE)}

This statistic measures the total deviation of the response values from the fit to the response values.

$$
\mathrm{SSE}=\sum_{i=1}^{\mathrm{n}}\left(\mathrm{y}_{i}-\forall_{i}\right)^{2}
$$

A value closer to 0 indicates that the model has a smaller random error component, and that the fit will be more useful for prediction.

\section{R-Square}

This statistic measures how successful the fit is in explaining the variation of the data. Thus, R-square is the square of the correlation between the response values and the predicted response values. R-square is defined as the ratio of the sum of squares of the regression (SSR) and the total sum of squares (SST). SSR is defined as,

$$
\mathrm{SSR}=\sum_{i=1}^{\mathrm{n}}\left(y_{i}-\mathrm{y}\right)^{2}
$$

SST is called the sum of squares about the mean, and is defined as,

$$
\mathrm{SST}=\sum_{i=1}^{\mathrm{n}}\left(\mathrm{y}_{i}-\mathbb{Y}\right)^{2}
$$

where,

$\mathrm{SST}=\mathrm{SSR}+\mathrm{SSE}$

Given these definitions, R-square is expressed as,

$$
\text { R-Square }=\mathrm{SSR} / \mathrm{SST}=1-(\mathrm{SSE} / \mathrm{SST})
$$

$\mathrm{R}$-square can take on any value between 0 and 1 , with a value closer to 1 indicating that a greater proportion of variance is accounted for by the model.

In this study, MATLAB software is used to perform the nonlinear regression analysis. 


\section{RESULTS}

Results are obtained for the following points of interest:-

- Voltage Profile Analysis

- Current Profile Analysis

- $\quad \mathrm{P}(\mathrm{pu}), \mathrm{Q}(\mathrm{pu}) \& \mathrm{~V}(\mathrm{pu}) \mathrm{Vs}$. Time Analysis

- $\quad \mathrm{P}(\mathrm{pu}) \& \mathrm{Q}(\mathrm{pu})$ Vs. Voltage Analysis

- Load Change Post Fault with respect to Voltage Sag

- Load Change During Fault with respect to Voltage Sag

Voltage is seen to gradually recover at all feeders. The full recovery of voltage is delayed due to re-connection of tripped load [1]. Voltage sag behavior of each phase is also clearly explained by the PSCAD Simulation performed. Voltage sags are seen to be longer for feeders closer to the fault point.

Current profile observations indicate that red phase current increase across all feeders during the fault. This could be caused by the nature of the fault. The Y-B-N fault on the HV side caused the yellow and blue phase current to drop to zero, leaving the red phase to supply the $132 / 33 \mathrm{kV}$ transformer for all 3 phases. This would lead to temporary increase in current on red phase during the fault. The surge in current before stabilizing at all phases for each feeder indicated a large percentage of motor load $[7,8,9]$. This would also account for the rise in red phase real power during the fault.

The active and reactive power for all phases and feeders is also seen to rapidly increase for a short instance of time after fault clearing to levels even above the pre-disturbance value. Surge of power is particularly overwhelming in terms of reactive power. This could be due to the reacceleration of motors, which requires high starting currents.

Upon voltage recovery, it is seen that certain feeders observed loads that are slightly higher that its pre-disturbance values. This type of load behavior has been observed for air conditioning load in previous studies [10]. A higher reactive load post-disturbance indicates that more reactive power is required to boost the supply following the voltage sag, as observed in many feeders. Most feeders showed a slightly higher operating voltage and lower real power readings post-disturbance. This is indicative that certain loads have failed to recover, boosting the voltage automatically.

Recovery time of the voltage increases as the severity increases. Load recovery time to point of stabilization which shows mixed results in this research, indicates that more sensitive load takes a much longer time to recover. Based on information from TNB Regional Control Centre in Figure 6, it can be seen that heavy industrial loads with more motors take a much longer time to recover.

\begin{tabular}{|l|l|}
\hline Feeder & Load Information \\
\hline BJLL4L5 & $\begin{array}{l}\text { PPU Taman Teknologi } \\
\text { (Astro, Tmn. Teknologi, Mimos, KOMDAQ) }\end{array}$ \\
\hline BTGA2L5 & SSU Chung Hwa (Plastic Factory) \\
\hline HCOM3L5 & $\begin{array}{l}\text { PPU Hicom E ( Metal Stamping, Teck See Plastic, } \\
\text { Kohno Plastic, Federal Paper) }\end{array}$ \\
\hline KLJT8L5 & $\begin{array}{l}\text { SSU Permodalan Nasional Bhd. \& PPU PNAL } \\
\text { (Bukit Bintang Commercial Complexes) }\end{array}$ \\
\hline MERU4L5 & PPU Puncak Alam ( Small Industrial Companies) \\
\hline PIDH2L5 & SSU M Food Factory \\
\hline PJST6L5 & PPU Dunlop (Dunlop, Bousted Switching) \\
\hline PMJU7L5 & SSU Texas Instruments (Electronic Manufacturing) \\
\hline PROT3L5 & SSU Nissan IOI (Car Manufacturing) \\
\hline SHAE8L5 & SSU Nippon Electric Glass Factory No.2 \\
\hline SRDG1L5 & PPU Perindustrian Bukit Serdang \\
\hline
\end{tabular}

Figure 6: Load Information for Individual Feeders

Figure 7,8 and 9 indicate results for load-voltage dependency based on post fault load change.

\begin{tabular}{|c|c|c|}
\hline \multicolumn{3}{|c|}{ RED PHASE } \\
\hline Feeder & dp(pre-post)/dv(fault) & dq(pre-post)/dv(fault) \\
\hline BJLL4L5 & 0.778 & 1.926 \\
\hline BTGA2L5 & 0.444 & 0.333 \\
\hline HCOM3L5 & 0.370 & 0.444 \\
\hline KLJT8L5 & 0.084 & -0.335 \\
\hline MERU4L5 & -0.179 & -0.893 \\
\hline NUNI13L5 & 0.082 & -0.164 \\
\hline PIDH2L5 & 0.105 & -1.263 \\
\hline PJST6L5 & 0.433 & 0.767 \\
\hline PMJU7L5 & 0.393 & -0.429 \\
\hline PROT3L5 & 2.630 & -4.889 \\
\hline SHAE8L5 & 0.185 & 0.519 \\
\hline SRDG1L5 & 0.167 & -0.333 \\
\hline TMSY2L5 & 0.267 & -1.367 \\
\hline
\end{tabular}

Figure 7 : Load Change Post Fault with respect to Voltage Sag for Red Phase

\begin{tabular}{|c|c|c|}
\hline \multicolumn{3}{|c|}{ YELLOW PHASE } \\
\hline Feeder & dp(pre-post)/dv(fault) & dq(pre-post)/dv(fault) \\
\hline BJLL4L5 & 1.080 & 2.160 \\
\hline BTGA2L5 & 0.708 & 1.083 \\
\hline HCOM3L5 & 0.667 & 0.667 \\
\hline KLJT\&L5 & 0.087 & -0.174 \\
\hline MERU4L5 & 0.056 & -0.500 \\
\hline NUNI13L5 & 0.435 & 0.174 \\
\hline PIDH2L5 & 0.433 & -0.577 \\
\hline PJST6L5 & 0.846 & 0.962 \\
\hline PMJU7L5 & 0.760 & -0.320 \\
\hline PROT3L5 & 3.217 & -6.696 \\
\hline SHAE8L5 & 0.458 & 0.167 \\
\hline SRDG1L5 & 0.080 & -0.600 \\
\hline TMSY2L5 & 0.538 & -1.500 \\
\hline
\end{tabular}

Figure 8 : Load Change Post Fault with respect to Voltage Sag for Yellow Phase

\begin{tabular}{|c|c|c|}
\hline \multicolumn{3}{|c|}{ BLUE PHASE } \\
\hline Feeder & dp(pre-post)/dv(fault) & dq(pre-post)/dv(fault) \\
\hline BJLL4L5 & 0.322 & 0.831 \\
\hline BTGA2L5 & 0.241 & 0.741 \\
\hline HCOM3L5 & 0.224 & 0.414 \\
\hline KLJT8L5 & -0.018 & -0.073 \\
\hline MERU4L5 & -0.027 & -0.109 \\
\hline NUNI13L5 & 0.109 & 0.273 \\
\hline PIDH2L5 & 0.067 & 0.044 \\
\hline PJST6L5 & 0.233 & 0.616 \\
\hline PMJU7L5 & 0.225 & 0.085 \\
\hline PROT3L5 & 1.259 & -2.759 \\
\hline SHAE8L5 & 0.169 & 0.288 \\
\hline SRDG1L5 & -0.026 & -0.132 \\
\hline TMSY2L5 & 0.183 & -0.085 \\
\hline
\end{tabular}

Figure 9 : Load Change Post Fault with respect to Voltage Sag for Blue Phase

The load change post fault compared to voltage sag indicates that KLJT is least dependent to voltage. This could be because the fault occurred on a Saturday morning where many of the offices were not operating. Since KLJT is mainly made up of commercial load, the effect would have been severe if the fault were to occur on a weekday during working hours. BJLL and PROT showed highest dependency since both a technology based industries which would have been operating as usual on a Saturday morning.

Figure 10, 11 and 12 indicate results from MATLAB simulation to analyze load-voltage dependency during fault. 


\begin{tabular}{|l|l|l|l|l|l|l|}
\hline \multicolumn{7}{|c|}{ RED PHASE } \\
\hline \multicolumn{1}{|c|}{ Feeder } & $\mathbf{d p / d v}$ & $\mathbf{R}^{\mathbf{2}}$ & $\mathbf{S S E}$ & $\mathbf{d q} / \mathbf{d v}$ & $\mathbf{R}^{2}$ & $\mathbf{S S E}$ \\
\hline BJLL4L5 & -2.583 & 0.7164 & 0.622 & 9.467 & 0.5622 & 20.38 \\
\hline BTGA2L5 & -2.026 & 0.7567 & 0.2777 & 7.293 & 0.2477 & 19.84 \\
\hline HCOM3L5 & -2.186 & 0.7914 & 0.2421 & 8.124 & 0.6164 & 10.57 \\
\hline KLJT8L5 & -1.142 & 0.8508 & 0.1655 & 2.665 & 0.8836 & 0.5799 \\
\hline MERU4L5 & -1.729 & 0.7773 & 0.2672 & 16.37 & 0.6918 & 10.64 \\
\hline NUNI13L5 & -3.048 & 0.8993 & 0.4442 & 7.031 & 0.6384 & 10.82 \\
\hline PIDH2L5 & -3.997 & 0.8544 & 0.7715 & 13.38 & 0.5232 & 24.77 \\
\hline PJST6L5 & -3.370 & 0.7903 & 0.8616 & 9.373 & 0.2277 & 64 \\
\hline PMJU7L5 & -2.064 & 0.7863 & 0.2274 & 3.330 & 0.7709 & 2.753 \\
\hline PROT3L5 & -2.548 & 0.7199 & 0.6602 & 4.286 & 0.6767 & 0.5003 \\
\hline SHAE8L5 & -0.9069 & 0.7061 & 0.1221 & 5.375 & 0.6285 & 4.262 \\
\hline SRDG1L5 & -1.536 & 0.8170 & 0.2812 & 5.077 & 0.7070 & 5.284 \\
\hline TMSY2L5 & -1.948 & 0.8098 & 0.5228 & 13.39 & 0.3345 & 46.61 \\
\hline
\end{tabular}

Figure 10: Load Change During Fault with respect to Voltage Sag for Red Phase Using MATLAB Simulation

\begin{tabular}{|l|l|l|l|l|l|l|}
\hline \multicolumn{7}{|c|}{ YELLOW PHASE } \\
\hline \multicolumn{1}{|c|}{ Feeder } & \multicolumn{1}{|c|}{$\mathbf{d p / d v}$} & \multicolumn{1}{|c|}{$\mathbf{R}^{2}$} & \multicolumn{1}{|c|}{$\mathbf{S S E}$} & $\mathbf{d q} / \mathbf{d v}$ & \multicolumn{1}{|c|}{$\mathbf{R}^{2}$} & \multicolumn{1}{|c|}{ SSE } \\
\hline BJLL4L5 & 4.872 & 0.8979 & 0.1687 & 20.22 & 0.6286 & 59.27 \\
\hline BTGA2L5 & 6.085 & 0.9413 & 0.1391 & 6.097 & 0.9448 & 0.1392 \\
\hline HCOM3L55 & 6.797 & 0.9112 & 0.2566 & 6.646 & 0.9201 & 0.247 \\
\hline KLJT8L5 & 4.879 & 0.8831 & 0.2776 & 4.381 & 0.8991 & 0.1247 \\
\hline MERU4L5 & 7.320 & 0.9560 & 0.179 & 3.002 & 0.3439 & 3.384 \\
\hline NUNI13L5 & 5.143 & 0.9374 & 0.1123 & 5.097 & 0.9374 & 0.1102 \\
\hline PIDH2L5 & 10.200 & 0.8420 & 1.001 & 8.619 & 0.9305 & 0.2455 \\
\hline PJST6L5 & 3.827 & 0.9017 & 0.108 & 4.484 & 0.9004 & 0.2069 \\
\hline PMJU7L5 & 5.876 & 0.8723 & 0.3231 & 6.125 & 0.8936 & 0.3413 \\
\hline PROT3L5 & 4.593 & 0.9767 & 0.0349 & 5.818 & 0.7209 & 13.39 \\
\hline SHAE8L5 & 3.609 & 0.9595 & 0.04187 & 3.621 & 0.9624 & 0.04688 \\
\hline SRDG1L5 & 4.408 & 0.8883 & 0.1637 & 4.498 & 0.8945 & 0.1723 \\
\hline TMSY2L5 & 4.785 & 0.9345 & 0.09851 & 4.785 & 0.9345 & 0.09726 \\
\hline
\end{tabular}

Figure 11: Load Change During Fault with respect to Voltage Sag for Yellow Phase Using MATLAB Simulation

\begin{tabular}{|c|c|c|c|c|c|c|}
\hline \multicolumn{7}{|c|}{ BLUE PHASE } \\
\hline Feeder & $d p / d v$ & $\mathbf{R}^{2}$ & SSE & $\mathrm{dg} / \mathrm{dv}$ & $\mathrm{R}^{2}$ & SSE \\
\hline BJLL4L5 & 1.690 & 0.7229 & 5.677 & 4.295 & 0.4705 & 62.42 \\
\hline BTGA2L5 & 2.162 & 0.6105 & 7.117 & 5.517 & 0.5928 & 187.3 \\
\hline HCOM3L5 & 2.201 & 0.6307 & 6.131 & 6.508 & 0.5586 & 78.03 \\
\hline KLJT8L5 & 2.996 & 0.9553 & 0.01122 & 2.996 & 0.9553 & 0.01125 \\
\hline MERU4L5 & 2.128 & 0.8989 & 0.0171 & 13.450 & 0.6006 & 87.11 \\
\hline NUNI13L5 & 2.183 & 0.5992 & 6.805 & 7.850 & 0.4840 & 66.94 \\
\hline PIDH2L5 & 2.165 & 0.4135 & 14.46 & 10.370 & 0.6058 & 171.7 \\
\hline 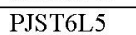 & 1.743 & 0.6242 & 10.33 & 3.944 & 0.5007 & 89.07 \\
\hline PMJU7L5 & 1.338 & 0.6311 & 0.04208 & 4.830 & 0.5050 & 45.5 \\
\hline PROT3L5 & 1.411 & 0.5417 & 8.982 & 2.507 & 0.6681 & 72.98 \\
\hline SHAE8L5 & 1.402 & 0.8793 & 0.009415 & 7.456 & 0.5129 & 47.54 \\
\hline SRDG1L5 & 1.401 & 0.8373 & 0.01824 & 3.256 & 0.3356 & 37.96 \\
\hline TMSY2L5 & 1.894 & 0.7191 & 5.424 & 3.846 & 0.3611 & 57.91 \\
\hline
\end{tabular}

Figure 12 : Load Change During Fault with respect to Voltage Sag for Blue Phase Using MATLAB Simulation

It is seen that load change during fault compared to voltage sag also indicates the same reasoning. It is seen that industries, namely factory based loads showed higher sensitivity compared to commercial based loads.

MATLAB modeling clearly indicated that real power was more accurately computed compared to reactive power. It is also seen that the severity of the disturbances accentuates the nonlinear behavior of the load. This is noticed at the blue phase especially. Thus, accuracy of the simulation was indeed questionable for larger voltage sags. It is also seen that general linear calculations as done previously [4] shows values that are much less sensitive compared to the actual situation.

\section{CONCLUSION}

Through PSCAD simulation it is shown that a double phase to ground fault on the transmission line causes all three voltage phases to sag. This simulation matches the actual voltage sag seen from the measured feeder data. An identification procedure to estimate load dependency to voltage is also investigated. The non-linear Least Squares Regression method is finally chosen and implemented using MATLAB. Since, varying phase angle values were not directly measured, a method was devised to calculate these values which were needed to calculate real and reactive power. It is found that all feeders in question supply heavy commercial and industrial loads.

The surge in current, real and reactive power before stabilizing to post-disturbance values indicate motor and air conditioning loads are involved. Through comparative analysis and plotting of graphs, it can be seen that the larger the voltage sag for a particular phase of a feeder, the slower the recovery time. However, when comparing between feeders, the inherent nature or type of the load connected dictates how fast the recovery takes. The nature of the load at the particular time of the fault also dictates the value of the post disturbance voltage and power.

Analysis also indicates that the larger the voltage sag, the nonlinear behavior of the load accentuates. This explains the MATLAB statistical analysis for blue phase reactive power results in particular. Thus, the static load model can only be used for small voltage variations of sensitive feeder loads. A proper comparison between feeders can only be justified with better information on various aspects of the feeder including daily load demand profile, seasonal load variations and customer habits through out a long term period.

Location of the feeder from point of fault also plays an important role. Certain feeders exhibited more serious conditions compared to others during the fault. Load at KLJT is seen to have been least affected by voltage, while BJLL and PROT seem to be most affected by voltage.

For future work, steady state data should be made available to analyze the load response to voltage during small voltage variations. Data should be taken for various parts of each day, each week for a one-year period to see the effect of weather and time difference on load. High and low peak demand; determination of daily, weekly and seasonal load patterns based on weather conditions and customer habits in the area should be analyzed for a long term period. This would give a more realistic picture of the load response to voltage. This would mean more rigorous metering and data collection than what is presently available. Direct measurement of phase angles should be also made available for ease of computation. Dynamic load modeling should be tested out for faults with large voltage sags. Also, dynamic load modeling could provide better results for reactive power analysis for sensitive feeders with high amounts of motor loads. In addition to the current information collected, limiting factors such as stability limits, and other possible weak points of the system should be accounted for. A survey could also be conducted regarding the main components present in the load area; motors, electric heating, boilers, pumps, air conditioner units, lighting, tap changers and reactive compensation in the area. 


\section{REFERENCES}

[1] Ines Romero Navarro, "Dynamic Power System Load : Estimation of Parameters from Operational Data", Lund University, Sweden, 2005

[2] William W. Price, Kim A. Wirgau, Alexander Murdoch, James V. Mitsche, Ebrahim Vaahedi, Moe A. El-Kady, "Load Modeling for Power Flow and Transient Stability Computer Studies", IEEE Transactions on Power Systems, Vol.3, No.1, February 1988

[3] Carson W. Taylor, "Power System Voltage Stability", EPRI, McGraw Hill Inc.1994

[4] Chia-Jen Lin, Yung-Tien Chen, Chiew-Yann Chiou, ChangHorng Huang, Hsiao-Dong Chiang, Jin-Cheng Wang, Lazhar FeikhAhmed, "Dynamic Load Models in Power Systems Using the Measurement Approach", IEEE Transactions on Power Systems, Vol.8, No.1, February 1993

[5] Daniel Karlsson, David J. Hill, "Modeling and Identification of Nonlinear Dynamic Loads in Power Systems", IEEE Transactions on Power Systems, Vol.9, No.1, February 1994

[6] Alf Dwyer, Ron E. Nielsen, Joerg Stangl, Nokhum S. Markushevich, "Load to Voltage Dependency Tests at B.C. Hydro", IEEE Transactions on Power Systems, Vol.10, No.2, May 1995

[7] I.A. Hiskens, J.V. Milanovic, "Load Modeling in Studies of Power System Damping", IEEE Transactions on Power Systems, Vol.10, No.4, November 1995

[8] B. Sawir, M.R. Ghani, A.A. Zin, A.H. Yatim, H. Shaibon, K.L. Lo, "Voltage Sag: Malaysian's Experience", IEEE, 1998

[9] K. Tomiyama, S. Ueoka, T. Takano, I Iyoda, K. Matsuno, K. Temma, J. J. Paserba, " Modeling of Load During and After System Faults Based on Actual Field Data", IEEE Transactions on Power System

[10] Emil Kermendey, Nervis Villalobos, Martin Schmieg, "The Impact of Load Behaviour on Voltage Stability, an Application Case in ENELVEN/VENEZUELA"

\section{BIOGRAPHIES}

Abu Bakar was born in Malaysia on March 13, 1953. He graduated from Southampton University, UK with a B Sc. (Hons) in 1976, M Eng. and $\mathrm{PhD}$ from University Technology Malaysia in 1996 and 2004. His employment experience is with Tenaga Nasional Berhad (TNB) for the past 25 years. He has been involved in several conferences overseas and locally such as Vice-Chairman (Technical) CEPSI-1996, Committee Member CIGRE Symposium Malaysia 1999, Corresponding Member IEE $7^{\text {th }}$ International Conference on Development in Power System Protection, Amsterdam 2001 and Committee Member $3^{\text {id }}$ TNB Technical Conference 2001, Malaysia. He is responsible for establishing the RTDS test lab in TNB for relay acceptance. Currently, he is the General Manager for Maintenance, Transmission Division TNB.

Salleh began his engineering career in NEB (National Electricity Board) - a state owned electric utility in Malaysia - in 1978 as an Assistant Distribution Engineer after graduating from Southampton University, United Kingdom. He obtained MEE (Masters in Electrical Engineering) degree from UTM (Universiti Teknologi Malaysia, Kuala Lumpur) in 1989 on a research work entitled 'Optimization of Distribution System Losses'. In 1990, he left for Canada to pursue his doctorate in 'Parallel Distributed Computation of Transient Stability Problem's at McMaster University in Hamilton. He completed his doctorate in 1993. Dr Salleh joined PTI in its Malaysian's office as a Senior Consultant in July 1995. Dr Salleh is a member of CIGRE and has been organizing and coordinating the technical activities of the Malaysian National Committee of CIGRE since 1996. He is involved in CIGRE Working Groups WG37.25, secretary to two working groups WG37.26 and WG37.32. He jointly received CIGRE Study Committee 37 Award for the best working group on industry restructuring and reform status' in 2003. He was the secretary of Asia-Oceania Regional Council of CIGRE between 2002 and 2004. $\mathrm{He}$ is also a member of the IEEE Power Engineering Society and the recipient Engineer of the Year Award Malaysia for 2003. He is also active in CIRED Malaysia and has been involved as committee members particularly in organization of technical conferences and workshops. Since November 2000, he has been with Advanced Power Solutions Sdn. Bhd. (APS) of Malaysia. Since with APS, Dr Salleh has been heavily involved in development and worldwide supports of PTI software products notably the PSS/Engines. At the same time he continues to provide consulting and educational services in the region.

Malini Satchiananda was born in Malaysia on June 19, 1980. She graduated from University Technology Malaysia with a B Eng. (Hons) in Electrical Engineering. She is currently pursuing her $M$ Eng. in Electrical Energy and Power Systems in University Malaya, Malaysia. She has worked on secondary protection design and relay applications in Areva T\&D Malaysia for 4 years. She is currently attached to GE Energy, Malaysia.

Saad Mekhilef received a B Eng. ( $1^{\text {st }}$ Class) degree in Electrical Engineering from University of Setif in 1994, M Eng. and PhD from University Malaya in 1998 and 2003 respectively. He is currently a lecturer at Dept. of Electrical Engineering in University Malaya. He is also the Deputy Director for the Centre for Research in Power Electronics \& Drives, Automation and Control. Dr. Saad is the author and co-author of more than 50 publications in international journals and proceedings. He is actively involved in industrial consultancy for major corporations in power electronics projects. His research interests include industrial electronics, power conversion techniques, control of power converters, renewable energy and energy efficiency. 